\title{
Adoption of Improved Dryland Practices of Greengram Cultivation among the Farmers in Semi-Arid Zone of Andhra Pradesh, India
}

\author{
K. Balaji Naik* and Varaprasada Rao
}

Krishi Vigyan Kendra., Darsi, Prakasam (District), India

*Corresponding author

\section{A B S T R A C T}

Keywords

Greengram

Cultivation,

Dryland Practices

Semi-Arid Zone

Article Info

Accepted: 06 September 2018

Available Online:

10 October 2018
Adoption of improved agricultural practices among the farmers is one of the most critical factors for development of the country. Adoption of improved agricultural practices is a dynamic and complex process. Scientists, extension workers and various other agencies contribute to accelerating the adoption of improved agricultural practices. Each of them has a distinct role in promoting the adoption of improved agricultural practices. Nevertheless, it is the farmers who occupy central position in this scheme because it is they who take the decision to adopt or reject. The farmers do not adopt new agricultural practices without giving thought to the matter, or on merely being told to do so.

\section{Introduction}

Several factors influence them in adoption of improved agricultural practices. Some factors help them to adopt improved agricultural practices. Each of them has a distinct role in promoting the adoption of improved agricultural practices. Nevertheless, it is the farmers who occupy central position in this scheme because it is they who take the decision to adopt or reject any improved agricultural practices. The farmers do not adopt new agricultural practices without giving thought to the matter, or on merely being told to do so. Several factors influence them in adoption of improved agricultural practices. Some factors help them to adopt improved agricultural practices while some factors prevent them from adopting these practices. This paper discusses how the farmers adopt improved agricultural practices, what factors influence them to adopt improved 
agricultural practices, what are the obstructing causes preventing adoption of improved agricultural practices. This paper also suggests ways to overcome the problems in adoption of improved agricultural practices.

\section{Materials and Methods}

The study was conducted in a village (Guruva vajipeta) in Kanigiri Mandal of Prakasam district of Andhra Pradesh. The farming in the village is entirely dry land farming since the farmers have no source of water cultivation except rains. The dry land farmers were the respondents. The sample respondents belonged to three categories of farmermarginal, small and big farmers. The total sample respondents were 45 consisting of marginal, small and big farmers. From each selected family, the head of the household was chosen as the respondent. The data were collected from the respondents through personal interview at their households.

Green gram is an important pulse crop and is mainly grown as a cash crop. Improved dry land practices of green gram cultivation undertaken for the study were: land preparation, sowing time, improved variety, seed rate, plant geometry, farmyard manure, compost, vermi-compost, chemical fertilizer, weeding time, fungicide and insecticide. The respondent were put the question "Do you adopt?" for each selected practice. The respondents were recorded in one of the two columns, "Yes" and "No". The respondents who did not adopt a certain practices were requested to indicate the constraints why they did not adopt the practice. The responses were collected and the content analysis was done.

\section{Results and Discussion}

\section{Land preparation and sowing}

The recommended practice is to plough the field twice and sow green gram between the first week of July and the first week of August. These operations are done now by tractor. But in the past the only sources of power were bullocks and cows. In the past, the size of holdings was quite large and a portion of land was left fallow for two to three years. That part of the land was used for grazing animals during this period. A part of the land was used for grazing animals during this period. Another reason was is scarcity of rainfall, it is not possible to cover the whole area for Agricultural use. Besides, maintaining a pair of bullock or cows for field preparation all the farmers are now using tractors drawn implements either of their own or hired from others, for all field operations. The tractor is also used to bring produce after harvest of the crop from the threshing yard. Tractor owners take their tractor to neighbouring states after the kharif season and earn money there.

After receiving the rainfall the farmers plough the field for two to three times for preparing the field for cultivation of crops. If the moisture is sufficient, the rainfall is considered sufficient for sowing. The ploughing and sowing operations are completed in the shortest possible time by continually operating the tractor day and night. The reason is that rain, which is a very critical factor for the area, is not certain/if the rainfall occurs before the first week of July, the farmers start sowing as rainfall is not certain.

When the rainfall occurs the farmers rush to sow the seed at the earliest to utilize the available moisture. It was not possible in the past to carry out sowing in the quickest possible time and utilize the available moisture because only bullocks and cows were available for ploughing which were much slower.

Earlier sowing was done by drilling by one 
person putting the seed through a funnel called nai. However, now tractor drawn tubes are connected with the funnel and seed is poured through the funnel. Payment to tractor owner is on the basis of the time taken. He is paid immediately after the operations by most farmers, through sometimes after the harvest.

\section{Improved variety}

Many Greengram varieties (L.G.G-460, T.M96-2 and IPM-2-14) have been recommended for the area half of the respondents adopted improved variety showing that there is moderate adoption of improved variety of green gram among the farmers. Table-1

\section{Seed rate}

The respondents did not adopt the recommended seed rate $(15-20 \mathrm{ka} / \mathrm{ha})$. They used $10 \mathrm{~kg} / \mathrm{ha}$ (Table 1). The farmer sowed mostly the local variety in which the plant has more height with spread out branches, therefore they preferred less seed rate. They also reported that there would be less distance between one plant and to another if higher seed rate was used, and there would be fewer yields.

\section{Plant geometry}

As per recommendation the respondents kept a distance of a $30 \mathrm{~cm}$ from one line to another for sowing green gram. There should be a uniform distance of $10 \mathrm{~cm}$ from plant to plant. The respondents knew it and disclosed that a uniform distance from plant to plant is essential for good crop yield. But they did not follow it because they did not follow it because they did not have planters to maintain this distance. The seed were sown by hand. Hence they fell very close at some places and far apart at other places. Thus the crop did not get the same amount of moisture and nutrients from the soil.

\section{Farm yard manure}

Nearly all respondents applied farm yard manure for greengram as they had livestock and they considered it very useful to crop. The average dose of application of farmyard manure was $4.10 \mathrm{t} / \mathrm{ha}$ that was far less than recommended dose (15-20 t/ha). The respondents who did not apply it reported that they did not have farmyard manure as they used it for fuel.

\section{Compost}

Farmyard manure is raw dung when the farmers apply it in the field. Mostly it is not well decomposed because of high temperature and lack of rainfall. It does not substantially add either to the soil's physical quality or soil fertility. For better use of manure the technique of making compost should be followed. None of the respondents adopted compost technique as they were not aware of it.

\section{Vermi- compost}

None of the respondents adopted vermicompost technique as they were not aware of it.

\section{Rhizobium culture}

None of the respondents adopted Rhizobium culture as they did not have knowledge of it.

\section{Chemical fertilizer}

More than half of the respondents applied chemical fertilizer (table 1).the average dose use of the respondents in a hectare was 3.20 $\mathrm{kg} \mathrm{N}$ nitrogenous and $2.90 \mathrm{~kg} \mathrm{P}_{2} \mathrm{O}_{5}$. The applied quantity of chemical fertilizer was far below the recommended dose (10-12 kg N and 30-40 kg $\mathrm{P}_{2} \mathrm{O}_{5}$ ). 
Forty-two percent respondents did not apply chemical fertilizer.38.88 percent respondents reported that low rainfall was the reason for not applied of chemical fertilizer. They disclosed that the crop could not benefit from chemical fertilizers there was lack of moisture in the soil owing to fast evaporation of moisture from sandy soil and high temperature in the area.

Further, 16.66 percent respondents reported that if chemical fertilizer was applied it would degrade the soil. 38.88 percent respondents reported that there was no need of application of chemical fertilizer as they were applying farm-yard manure. 38.88 percent respondents reported that they could not afford to purchase costly chemical fertilizer (Table 2).

\section{Weed management}

All respondents reported that they completed the weeding within 20 to30 days of sowing as per recommendation. Weeding is done manually with a hand hoe by the members of family. In the weeding operation weeds were removed and also the soil crust pulverizes the top soil and serves as soil mulch. The respondents are very particulars are very particular about weeding because they consider that if weeds are not removed they will have an adverse effect on the crop growth. Another favourable factor is that there is no cost involved in weeding operation as it is done by the family itself.

\section{Fungicide}

None of the respondents applied fungicide. A very large percentage of the respondents (95.53\%) reported lack of knowledge for nonadoption of fungicide to control plant disease. A very small number of respondents $(2.22 \%)$ reported lack of money as well as absence of diseases in the plants as reasons for not using fungicide.

\section{Insecticide}

A very high percentage of respondents $(93.33 \%)$ applied insecticide to control insecticide to control insects. They used 6.30 $\mathrm{kg}$ Methyl Parathion which is far below the recommended dose (20-25 kg). The respondents mix 2 to $5 \mathrm{~kg}$ of ash with Methyl Parathion and broadcast it in the field. A few respondents $(6.67 \%)$ did not napply insecticide to their crop of green gram. Onethird of these respondents did not have knowledge of insecticides and two-thirds of the respondents $(66.66 \%)$ considered that it was sin to kill insects as they were also living organisms.

Suggestion to overcome problems in the adoption of improved dry land practices of green gram

There was a moderate adoption of the moderate variety of green gram among the farmers in the study area. It is of utmost importance that farmers should adopt the package of improved practices of green gram cultivation to get maximum benefits from the improved variety. The farmers were not aware of planter to sow the seeds at equal and correct distance between them.

Knowledge of the innovation is indeed a precondition for adoption of the innovation as there can be no adoption without knowledge. The knowledge of improved agricultural practices can be imparted significantly through intensive extension educational efforts. A vigorous effort should be made to impart knowledge and skill to the farmers about improved agricultural practices. Adequate knowledge will motivate and inspire them to try and practice whatever is feasible in their situation. The developmental agency has to be ready with timely availability of good quality inputs in adequate amounts to fulfil the farmers' demands. 

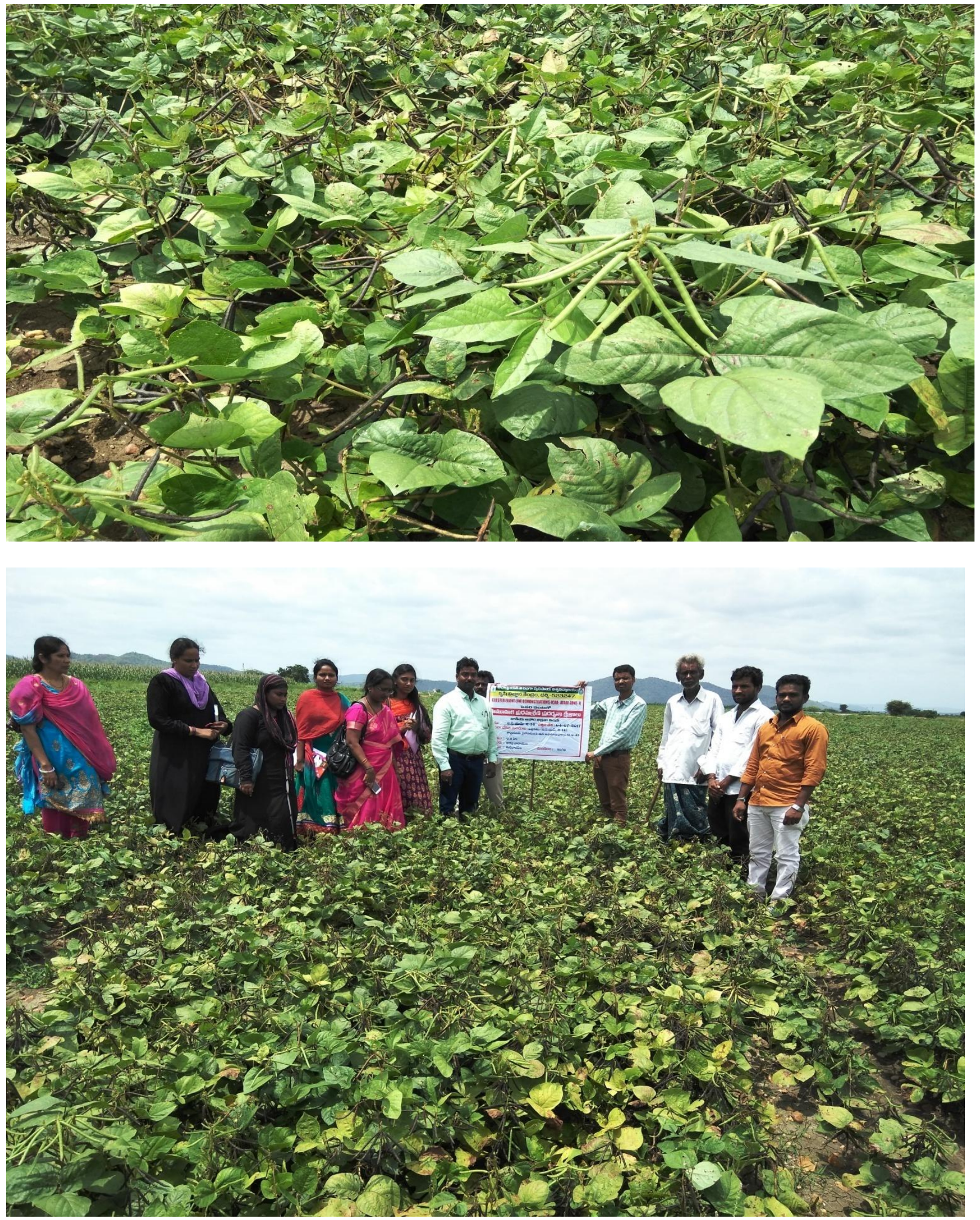
Table.1 Respondents who adopted improved dry land farming practices of green gram cultivation

\begin{tabular}{l|l|l|}
\hline S.no. & \multicolumn{1}{|c|}{ Recommended improved ry land practices of green gram cultivation } & Adoption $(\mathrm{N}=45) \%$ \\
\hline $\mathbf{1}$ & Land preparation - two ploughings & 100.00 \\
$\mathbf{2}$ & Sowing time between the first week and the first week of August & 100.00 \\
$\mathbf{3}$ & Improved variety & 46.66 \\
$\mathbf{4}$ & Seed rate $15-20 \mathrm{~kg} / \mathrm{hectare}$ & $10 \mathrm{~kg}$ \\
$\mathbf{5}$ & Row to row distance $30 \mathrm{~cm}$ & 100.00 \\
6 & Plant to plant distance $10 \mathrm{~cm}$ & 0.00 \\
7 & Farm yard manure & 91.11 \\
8 & Farm yard manure quantity $15-20$ tonnes/ hactare & 4.10 tonnes \\
9 & Compost & 0.00 \\
10 & Vermi- compost & 0.00 \\
11 & Rhizobium culture & 0.00 \\
12 & Chemical fertilizer & \\
13 & Chemical fertilizer dose $10-15 \mathrm{~kg}$ N & 20 and 30 days of sowing \\
14 & Weeding time within 20 and 39 days of sowing & 0 \\
15 & Fungicide & 93.33 \\
16 & Insecticide &
\end{tabular}

The respondents who did not adopt improved variety cited several problems in its adoption.

Table.2 Constraints in adoption of improved dry land farming practices of green gram cultivation

\begin{tabular}{|c|c|c|}
\hline Constraints in adoption of improved dry land farming practices of green gram cultivation & $\mathrm{F}$ & $\%$ \\
\hline \multicolumn{3}{|l|}{ Improved variety $(\mathrm{n}=\mathbf{2 3})$} \\
\hline Less fodder is obtained when improved variety is used seed & 4 & 17.39 \\
\hline The height of plant is less when improved variety is used & 3 & 13.84 \\
\hline There is shattering of the seed in case of improved variety & 3 & 13.44 \\
\hline Local seed gives more yield than improved seed & 4 & 17.39 \\
\hline Improved seed requires more rainfall & 2 & 17.39 \\
\hline The cost of improved seed is high in the market & 3 & 13.33 \\
\hline Good quality improved variety is not available & 1 & 4.34 \\
\hline There is lack of money to buy improved variety which is expensive & 3 & 13.33 \\
\hline \multicolumn{3}{|l|}{ Do not have knowledge of improved variety } \\
\hline There is lack of money & 1 & 4.34 \\
\hline There is soil less fertile & 2 & 8.69 \\
\hline There is not enough land & 2 & 8.69 \\
\hline Sowing of seeds at a distance of $10 \mathrm{~cm}$ between them $(n=45)$ & 1 & 4.34 \\
\hline Non-availability of planters for sowing the crop at $10 \mathrm{~cm}$ distance from plant to plant & 45 & 100.00 \\
\hline \multicolumn{3}{|l|}{ Compost $(\mathrm{n}=\mathbf{4 5})$} \\
\hline Lack of knowledge concerning in compost & 45 & 100.00 \\
\hline Rhizobhium culture ( $n=45$ ) & 45 & 100.00 \\
\hline \multicolumn{3}{|l|}{ Chemical fertilizer ( $n=45)$} \\
\hline There is low rain fall & 7 & 38.88 \\
\hline Chemical fertilizer degrades soil & 3 & 16.66 \\
\hline There is lack of money & 7 & 38.88 \\
\hline Chemical fertilizer is costly & 1 & 5.53 \\
\hline Applying farm yard manure & 7 & 38.88 \\
\hline \multicolumn{3}{|l|}{ Fungicide ( $n=45)$} \\
\hline No knowledge & 43 & 95.53 \\
\hline Lack of money & 1 & 2.22 \\
\hline No attack of disease & 1 & 2.22 \\
\hline \multicolumn{3}{|l|}{ Insecticide $(n=3)$} \\
\hline It is sin to kill insects & 2 & 66.66 \\
\hline No knowledge of insecticide & 1 & 33.33 \\
\hline
\end{tabular}


The field extension workers has a great role in educating the farmers about improved agricultural practices, because he is in direct contact with the farmers is a difficult task since learning by the farmers is voluntary. Besides this, most pf the villagers are illiterate. It is therefore essential that field extension workers should win the farmers' trust and be a friends, philosopher and guide to them. They should have strong desire for the farmers' wellbeing and have patience as several problems arise in the transfer of improved agricultural practices. They should be well versed and confident in telling the farmers about of improved agricultural practices. They should also have full knowledge of the farmers' actual practices and the resources available to them. There should be provision in the organization to provide regular training to field extension workers on improved agricultural practices. They should also be provided training in extension methods.

There are several extension methods for educating the villagers about improved agricultural practices. The government should allocated adequate find for extension methods. Each extension methods has its own advantages and limitations. The field extension worker should select and use the method according to the needs of the area.

Individual contact between the field extension worker and the farmers is crucial in extension programme. Hence the field extension worker should select a harmful of farmers in each village. This is not with a view to benefit the selected group but to spread improved agricultural practices among the farmers through them. These farmers should have the following: (1) they should be literate, (2) should be prepared to listen to the field extension workers' advice, (3) should have resources to adopt the technology, and (4) possess zeal to spread among others what they have learnt. These core farmers should be selected after consultation with the villagers.

The farmers adopt an innovation when they see the results of the improved agricultural practices. Therefore the core farmers should be taken to the research station to show the results of improved agricultural practices. They should be provided practical training in improved agricultural practices. During practical training, neighbourhood farmers should be invited. The programme to demonstrate the results of improved agricultural practices should be organized at the core farmers' field. Field days should be conducted at the demonstration field to convince the farmers of advantages of improved agricultural practices. Attractive posters should be displayed at common sites to create awareness among the farmers and interest among the farmers in improved agricultural practices. Leaflets, radio cassettes and CDs on improved agricultural practices should be made for distribution among the farmers. Kisan melas should be organized at the headquarter each year. Such fairs provide opportunity to farmers to learn through observation and discussion with scientists and extension workers. Awards should be offered to progressive farmers to further motivate them for adoption of improved agricultural practices. Mass media - radio, television and newspaper - have been creating awareness of improved agricultural practices among the farmers. The media should allot more time to programmes on improved agricultural practices. The personnel in charge of preparation of the agricultural programme should have more contact with research institutes and state agricultural department. The personnel should visit villages and stay there for some days to understand the agricultural practices followed there and the problems in the adoption of new agricultural practices followed there and the problems in the adoption of new agricultural practices. 
This will help in making relevant programmes for the farmers.

The improved variety of green gram has spread fast among the farmers by word of mouth and also by their seeing themselves. The farmers saw the impact of the improved variety with respect to its resistant to YMV, vegetative growth, grain size and yield. The respondent who did not adopt the improved variety reported (a) less fodder production (b) shattering of pods, (c) low rainfall and (d) high cost of seed as problems in adoption of the improved variety of green gram. Hence the research institutes should develop an improved variety that produces more fodder and controls shattering of pods. The high cost of improved variety of green gram can be reduced if the farmers grow improved variety at their fields. The farmers should be educated by extension workers about the method of growing the improved variety. The cost of transport will be reduced, abd buying seeds will be cheaper. It will ensure availability of seeds in time which is is very important in the semi-arid area. The field extension workers should select a few progressive farmers and should educate them about growing of improved variety at their fields. As the seed technology involves several steps, the extension workers should be in close contact with the selected farmers for growing improved seeds of green gram.

This paper presents the results of the study made regarding the adoption of improved dry land farming practices of green gram cultivation among the dry land farmers. The data were collected from 45 dry land farmers in a village in an semi srid area of Prakasam during the 2017-18. The farmers were not aware of plant geometry, method of making compost and control measures for disease and insects of greengram. An all-out extension effort should be made to make the farmers knowledgeable about improved dry land practices, which is a pre- condition for the adoption of improved dry land practices. The respondents who did not adopt improved variety of green gram reported less fodder production, shattering of pods, low rain fall and high cost of seed as problem in adoption of improved variety of green gram. Hence research institute should develop improved variety that should provide fodder and reduce shuttering of pods. The high cost of the improved variety at their fields. The farmers should be educated by extension workers should be educated by extension workers about the method of growing the improved variety of green gram.

\section{References}

Singh, R.N. 2017. Adoption of improved dry land practices of green gram cultivation among the farmers in arid zone of rajasthan, Intensive agricultural vol.53, January-march.

Islam, Q. M. S., M.A.M. Miah, M.S. Rahman and M.S. Hossain. 2013. Adoption of BARI mung varieties and its constraints to higher production in southern region of Bangladesh. Bangladesh J. Agricultural Research, 38(1): 85-96.

\section{How to cite this article:}

Balaji Naik, K. and Varaprasada Rao. 2018. Adoption of Improved Dryland Practices of Greengram Cultivation among the Farmers in Semi-Arid Zone of Andhra Pradesh, India. Int.J.Curr.Microbiol.App.Sci. 7(10): 535-542. doi: https://doi.org/10.20546/ijcmas.2018.710.059 